\title{
PERANCANGAN E-COMMERCE JILBAB PADA WAYDEE PROJECT KUDUS
}

\author{
Triya Adzani Maulidina ${ }^{1}$, Nanik Susanti ${ }^{2}$, Noor Latifah ${ }^{3}$ \\ ${ }^{1}$ Program Studi Sistem Informasi, Fakultas Teknik, Universitas Muria Kudus \\ 2 Program Studi Sistem Informasi, Fakultas Teknik, Universitas Muria Kudus \\ ${ }^{3}$ Program Studi Sistem Informasi, Fakultas Teknik, Universitas Muria Kudus
}

Email: 'triyaadzani@gmail.com, ${ }^{2}$ nanik.susanti@umk.ac.id, ${ }^{3}$ noor.latifah@umk.ac.id,

(Naskah masuk: 24 Juni 2020, diterima untuk diterbitkan: 29 Juni 2020)

\begin{abstract}
Abstrak
Waydee Project merupakan sebuah tempat yang menjual jilbab yang berada di Kota Kudus. Pashmina dan model segiempat merupakan produk andalan pada toko ini. Penjualan produk masih dilakukan secara manual dengan cara konsumen datang langsung ke toko, meskipun sudah memanfaatkan media sosial namun masih terkendala dalam proses pengelolaanya. Tujuan dari penelitian ini adalah membantu waydee project dalam mengelola strategi pemasaran untuk mendapatkan konsumen sebanyak-banyaknya sehingga mampu meningkatkan penjualan produk. Metode penelitian dilakukan dengan cara pengumpulan data serta melakukan perancangan sistem informasi berorientasi objek menggunakan UML. Penelitian ini menghasilkan sebuah sistem informasi penjualan jilbab secara online (e-commerce) yang mampu memproses seluruh data penjualan serta pengelolaannya.
\end{abstract}

Kata kunci: e-commerce, jilbab, strategi pemasaran

\section{DESIGN OF HIJAB E-COMMERCE ON WAYDEE PROJECT KUDUS}

\begin{abstract}
The Waydee Project is a place that sells headscavers in the Kudus City. Pashmina and quadrilateral models are the mainstay products in this store. Product sales are still done manually by way of consumers coming directly to the store, even though they have used social media but are still constrained in the management process. The purpose of this research is to help waydee projects in managing marketing strategies to get as many consumers as possible so as to increase product sales. The research method is done by collecting data and designing objectoriented information systems using UML. This research resulted in an online hijab sales information system (ecommerce) that is able to process all sales data and its management.
\end{abstract}

Keywords: e-commerce, hijab, marketing strategy

\section{PENDAHULUAN}

Teknologi informasi di dunia saat ini telah mengalami perubahan secara pesat. Hal yang paling menonjol dalam perkembangan teknologi infromasi dan komunikasi adalah hadirnya teknologi baru yaitu berupa jaringan komputer yang terhubung ke seluruh dunia, yaitu internet. Di masa lalu, aktivitas perdangangan dilakukan melalui dengan menawar langsung barang yang akan dibeli, tapi pertumbuhan drastis dari internet dapat mengubah paradigma. Melalui internet, pedagang dapat menawarkan produknya secara online kepada pembeli tanpa bertatap muka. E-commerce mengizinkan penjual untuk menjual produk secara online.

Di Indonesia, fashion semakin berkembang pesat, khususnya untuk para muslimah, fashion muslimah yang dahulu berbeda dengan yang sekarang, apalagi wanita muslimah yang dahulu terkesan biasa saja dan kini muncul sebagai trendsetter bahkan sampai dunia. Dengan berkembangnya tren fashion islam masa kini, wanita dapat mengadopsi beberapa gaya modern, seperti jilbab yang dahulu hanya berfungki sebagai penutup aurat wanita kini bertambah fungsinya untuk mempercantik diri sehingga terlihat fashionable dan cantik.

Waydee project adalah sebuah branded yang bergerak dalam bidang penjualan di Kota Kudus yang menjual beberapa jenis jilbab, seperti pashmina dan segiempat. Namun, proses bisnis yang dilakukan saat ini masih dilakukan secara manual dimana konsumen melihat dan memilih jilbab yang diinginkan melalui instagram, lalu melakukan pemesanan kepada admin melalui whatsapp dan melakukan transaksi pembayaran yang bersamaan pada saat cash on delivery yang telah 
disepakati seelumnya. Untuk pengelolaan data penjualan yang dilakukan oleh owner pun masih menggunakan cara manual, yaitu menggunakan buku catatan penjualan. dan semakin banyak transaksi penjualan yang dilakukan maka menjadi penyebab sulitnya rekapitulasi data dan pembuatan laporan data penjualan.

Melihat perkembangan teknologi tersebut, maka permasalahan yang terjadi pada penjualan jilbab dapat diatasi dengan pembuatan sistem informasi. Sistem ini diharapkan mampu meningkatkan dalam penjualan jilbab dan lebih mudah serta cepat dikenal masyarakat luas. Sehingga terciptalah sebuah ide untuk membuat penelitian dengan judul "Sistem Informasi Pengelolaan Produksi dan Penjualan Jilbab Waydee Project Kudus berbasis Web".

\section{TINJAUAN PUSTAKA}

Prasetyo (2016) melakukan sebuah penelitian yang bertujuan untuk membangun Sistem informasi penjualan online tiwul instan pada PT. Cahaya Sejahtera Sentosa Blitar. Dengan adanya aplikasi sistem informasi pemesanan produk ini dapat memudahkan pelanggan dalam pencarian informasi tiwul instan dengan pemesanan produk yang cukup mudah dengan bergabung menjadi pelanggan atau member di dalam sistem informasi ini dan pembayaran dilakukkan melalui transfer bank.

Ferdika (2017) melakukan sebuah penelitian yang betujuan untuk membantu PT. Era Makmur Cahaya Damai supaya lebih efisien dalam transaksi penjualan dengan menggunakan teknologi website. Sistem ini dibangun untuk mempermudah proses penjualan, memudahkan pembeli dalam pembelian barang secara online, meningkatkan pendapatan dan memperluas promosi penjualan pada PT. Era Makmur Cahaya Damai.

Solihin (2017) melakukan sebuah penelitian yang bertujuan untuk membuat perancangan dan pembangunan aplikasi Sistem Informasi penjualan, pembelian dan persediaan suku cadang berbasis website. Hasil akhir dari perancangan dan pembangunan aplikasi sistem informasi ini adalah adanya sebuah aplikasi yang dapat memberi kemudahan transaksi penjualan, pembelian, dan persediaan suku cadang pada Bengkel Tiga Putra Motor Garut sehingga proses transaksi menjadi lebih efektif dan efisisen.

Asfinoza (2018) melakukan sebuah penelitian yang bertujuan untuk mengembangkan sistem informasi penjualan pada PT. Sri Aneka Karyatama dimana beberapa masalah seperti jarak antara pelanggan dan perusahaan dalam proses pemesanan pupuk, kesalahan dalam mencatat pesanan, membutuhkan waktu sedikit lebih lama dalam membuat laporan, dan begitu banyak pesaing sehingga perusahaan ini membutuhkan media dan alat yang angat besar. Sistem ini dikembangkan dalam bahasa pemrograman PHP dan MySql sebagai sistem manajemen basis data, pada sistem ini terdapat data produk, data penjualan, data pengiriman, data produk sampingan, data pemasok dan laporan penjualan, sehingga dengan adanya

Qomaruddin (2018) melakukan sebuah penelitan untuk mengembangkan Sistem Informasi Penjualan Batik Berbasis Web Pada Toko 10S Pasar Grosir Setono. Sistem Penjualan online yang dikembangkan dapat digunakan untuk mengelola data registrasi pelanggan, pembelian dan pemesanan barang, pengiriman barang, serta pemberitahuan informasi terbaru.

\section{METODOLOGI PENELITIAN}

\subsection{Metode Pengumpulan Data}

Dalam mendapatkan data yang lebih akurat, relevan, dan valid maka penulis menggunakan data dengan cara :

\subsubsection{Sumber Data Primer}

Sumber data primer adalah data yang diperoleh langsung dari instansi baik melalui tanya jawab, pengamatan langsung maupun pencatatan terhadap obyek penelitian. Sumber data primer dibagi menjadi 2 yaitu :

a. Wawancara

Pengumpulan data melalui tatap muka atau tanya jawab secara langsung dengan sumber data atau pihak-pihak yang berhubungan dengan penilitian. Misalnya dengan owner waydee project.

b. Observasi

Pengumpulan data melalui pengamatan dan pencatatan terhadap peristiwa yang terjadi secara langsung. Misalnya, penulis mencari data-data jilbab yang dibutuhkan dalam pembuatan sistem.

\subsubsection{Sumber Data Sekunder}

Sumber data sekunder adalah data yang diambil secara tidak langsung dari objek penelitian. Data ini diperoleh dari buku, dokumentasi, dan literatur-literatur, meliputi :

a. Studi Kepustakaan

Pengumpulan data dari buku-buku yang sesuai dengan tema permasalahan. Misalnya, pengumpulan teori-teori mengenai analisa dan desain untuk penyusunan skripsi.

b. Studi Dokumentasi

Pengumpulan data dari literature-literature dan dokumentasi dari internet, buku ataupun sumber infromasi lainnya. Studi dokumentasi penelitian ini adalah meminta data pembeli dari owner waydee project. Misalnya mengenai struktur organisasi, data pembeli dan lain-lainnya.

\subsection{Metode Pengembangan Sistem}

Metode pengembangan sistem yang digunakan adalah dengan menggunakan model air terjun (waterfall) sering juga disebut model sekuensial linier (sequential linier) atau alur hidup klasik (classic life cycle). Metode pengembangan sistem merupakan proses mengembangkan atau mengubah suatu sistem perangkat lunak dengan menggunakan metode-metode atau model-model yang digunakan 
orang untuk mengembangkan sistem-sistem perangkat lunak sebelumnya dengan memiliki alur hidup perangkat lunak secara sekuensial atau terurut dimulai dari analisis, desain, pengodean, pengujian, dan tahap pemeliharaan. (Rosa A, 2013)

Dalam pengembangannya metode waterfall memiliki beberapa tahapan diantaranya yaitu :

1. Analisis Kebutuhan Perangkat Lunak yaitu proses pengumpulan kebutuhan dilakukan secara intensif untuk menspesifikasikan kebutuhan perangkat lunak agar dapat dipahami perangkat lunak seperti apa yang dibutuhkan oleh pengguna meliputi data katalog produk, data kategori produk, data konsumen dan data jasa pengiriman, informasi pendaftaran pelanggan, informasi pemesanan serta informasi pembayaran.

2. Desain, proses multi-langkah yang berfokus pada desain manufaktur program perangkat lunak mencakup struktur data arsitektur perangkat lunak, representasi interface dan prosedur pengkodean.

3. Membuat kode program, desain harus diterjemahkan ke dalam sebuah program perangkat lunak. Hasil dari tahap ini adalah sebuah program komputer sesuai dengan desain yang telah dibuat pada tahap desain.

4. Pengujian berfokus pada software dalam hal logika dan fungsional dan menjamin bahwa semua bagian yang diuji. Hal ini dilakukan untuk meminimalkan kesalahan (error) dan menjamin hasil yang dihasilkan sesuai dengan yang diinginkan.

5. Pemeliharaan sistem, tidak menutup kemungkinan perubahan perangkat lunak saat dikirim ke pengguna. Perubahan bisa terjadi karena kesalahan yang terjadi dan bukan ketika diuji atau software terdeteksi harus disesuaikan dengan lingkungan baru.

\subsection{Metode Perancangan Sistem}

Unified Modelling Language (UML) adalah Metodologi kolaborasi antara metoda-metoda Booch, OMT (Object Modellinh Technique), serta OOSE (Object Oriented Software Enggineering) . UML terdiri dari banyak elemen-elemen grafis yang digabungkan membentuk diagram. Tujuan representasi elemen-elemen grafis ke dalam diagram untuk menyajikan beragam sudut pandang dari sebuah sistem berdasarkan fungsi masing-masing diagram tersebut.(Nugroho 2009)

Berikut ini jenis-jenis diagram Unified Modelling Language (UML) antara lain :

a. Use Case Diagram

Use Case Diagram adalah sebuah interaksi antara satu atau lebih actor dengan sistem informasi yang akan dibuat.

b. Class Diagram

Class Diagram adalah struktur sistem dari segi pendefinisian kelas-kelas yang akan dibuat untuk membangun sistem. Class memiliki apa yang disebut atribut dari metode atau operasi.

c. Sequence Diagram

Sequence Diagram adalah kelakuan objek pada user case dengan mendeskripsikan waktu hidup objek dan message yang dikirim dan diterima antar objek.

d. Activity Diagram

Activity Diagram adalah workflow atau aktivitas dari sebuah sistem atau proses bisnis atau menu yang ada pada perangkat lunak. Diagram aktivitas menggambarkan aktivitas sistem bukan apa yang dilakukan aktor.

e. Statechart Diagram

Statechart Diagram adalah perubahan status atau transisi status dari sebuah mesin atau sistem atau objek, diagram status digunakan untuk interaksi antar objek. Perubahan dibuat dalam suatu graf berarah.

\section{HASIL DAN PEMBAHASAN}

\subsection{Analisa dan Rancangan Sistem Baru}

Berdasarkan hasil observasi yang telah dilakukan mengenai alur proses bisnis yang ada pada waydee project selanjutnya pada penelitian ini dilakukan perancangan sistem baru yaitu model e-commerce yang dapat mempermudah dalam proses produksi barang sampai penjualan barang.

Adapun proses perancangan sistem baru model ecommerce ditunjukan oleh gambar 1 dibawah ini:

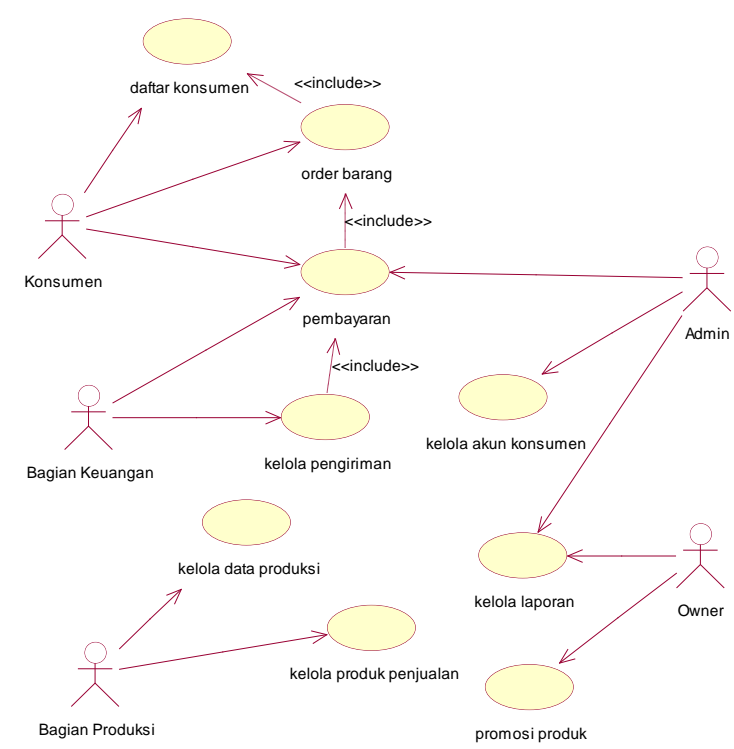

Gambar 1. Usecase sistem e-commerce jilbab

Dari perancangan usecase sistem e-commerce jilbab dihasilkan sebuah relasi tabel yang dapat mempermudah penyimpanan data dan pengelolaanya di dalam aplikasi. Berikut merupakan relasi tabel yang dihasilkan ditunjukan pada gambar 2. 


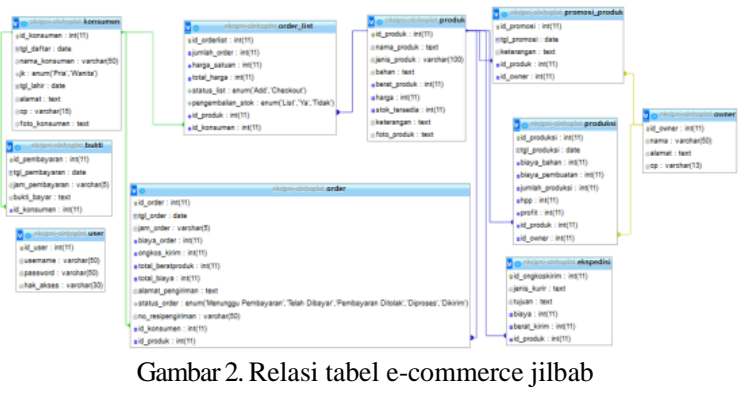

Tahapan dari penerapan dan pengujian hasil desain Sistem Informasi Pengelolaan Produksi Dan Perancangan e-commerce jilbab Waydee Project Kudus adalah implementasi sistem. Pada tahap pengembangan sistem perangkat lunak akan dilakukan implementasi hasil perancangan kedalam baris-baris kode program yang dapat dimengerti oleh komputer. Dalam pengoperasian perancangan e-commerce jilbab pada Waydee Project Kudus terdapat 3 pembagian hak akses user meliputi owner, admin dan konsumen. Berikut merupakan contoh perancangan layar antar muka aplikasi e-commerce jilbab pada Waydee Project Kudus

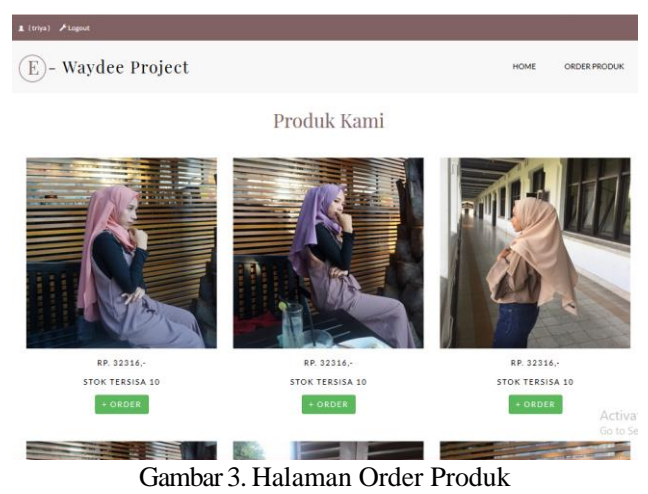

Halaman order produk ini merupakan tampilan menu untuk konsumen memilih jilbab yang akan dibeli. Lalu, setelah di klik order, konsumen dapat melihat beberapa pilihan warna dan detail fotonya. Dan setelah dipilih akan masuk kedaftar checkout.

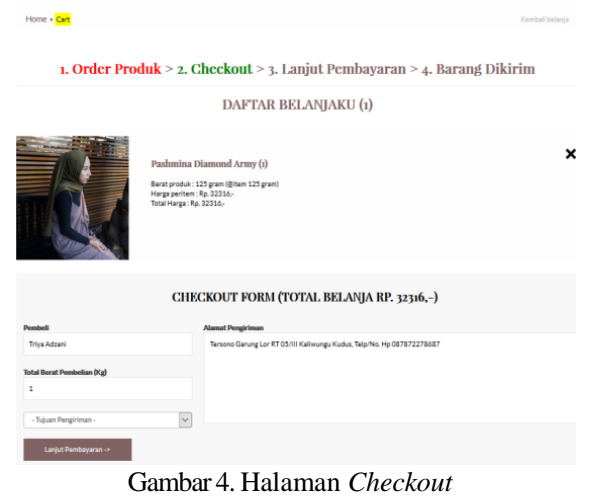

Halaman checkout ini merupakan tampilan setelah konsumen memilih jilbab diproses sebelumnya.
Dihalaman checkout terdapat form data diri konsumen dan alamat tujuan dimana jilbab akan dikirim setelah konsumen melakukan pembayaran.

\section{KESIMPULAN}

Setelah melakukan analisis, perancangan serta implementasi dan pembahasan pada bab-bab sebelumnya, maka dapat diperoleh kesimpulan sebagai berikut:

1. Menghasilkan sebuah sistem informasi penjualan jilbab secara online (e-commerce) yang mampu memproses seluruh data penjualan serta pengelolaannya..

2. Perancangan e-commerce ini digunakan owner untuk memberikan informasi mengenai jilbab yang akan dijual sehingga memudahkan konsumen untuk membeli jilbab secara lebih mudah yang dapat diakses secara online.

2. Sistem ini dapat menunjang proses produksi jilbab menjadi lebih baik lagi serta dapat mengatasi kendala-kendala yang ada. Sistem yang dibangun ini meliputi pengelolaan data user seperti owner, admin, dan konsumen.

\section{DAFTAR PUSTAKA}

Asfinoza, Puspasari, S., dan Sunardi, H., 2018, Sistem Informasi Penjualan Pupuk Berbasis Web pada PT. Sri Aneka Karyatama, Jurnal Media Infotama Vol. 14 No. 1.

Ferdika, M., dan Kuswara, H., 2017, Sistem Informasi Penjualan Berbasis Web Pada PT Era Makmur Cahaya Damai Bekasi, Information System for Educators and Professionals, Vol.1, No. 2, 175 -188, E-ISSN: 2548-3587.

H. M. Jogiyanto., 2005, Analisis \& Desain Sistem Informasi : Pendekatan Terstruktur Teori dan Praktik Aplikasi Bisnis, Andi Offset:Yogyakarta.

Nugroho, A., 2009, Rekayasa Perangkat Lunak Menggunakan UML dan Java, ANDI: Yogyakarta.

Prasetyo, A., dan Susanti, R., 2016, Sistem Informasi Penjualan Berbasis Web Pada PT. Cahaya Sejahtera Sentosa Blitar, Jurnal Ilmiah Teknologi dan Informasia ASIA (JITIKA), Vol.10, No.2, ISSN: 0852-730X.

Qomaruddin, M., dan Sudradjat, A., Sopandi, R., 2018, Sistem Informasi Penjualan Batik Berbasis Web Pada Toko 10S Pasar Grosir Setono, Publikasi Jurnal \& Penelitian Teknik Informatika, Volume 2 Nomor 2.

Rosa A.S., dan Shalahuddin, M., 2015, Rekayasa Perangkat Lunak Terstruktur dan Berorientasi Objek, Bandung:Informatika Bandung. Volume 3.

Solihin, H.,H, dan Nusa, A.,A.,F., 2017, Rancang Bangun Sistem Informasi Penjualan, Pembelian dan Persediaan Suku Cadang pada Bengkel Tiga Putra Motor Garut, Jurnal Infotronik Volume 2, No. 2. 